\title{
AN IOT BASED SMART BIN THAT GIVES REWARDS
}

\author{
Deepu K ${ }^{1}$, Akhil $C^{2}$, Anandu Krishna ${ }^{3}$, George Sebastian ${ }^{4}$ \\ ${ }^{1}$ APJ Abdul Kalam Technological University, India, deepukunjumon1231@gmail.com \\ ${ }^{2}$ APJ Abdul Kalam Technological University, India, akhilchandran723@ gmail.com \\ ${ }^{3}$ APJ Abdul Kalam Technological University, India, anandukrishna250@gmail.com \\ ${ }^{4}$ APJ Abdul Kalam Technological University, India, george.sebastian@mangalam.in
}

\section{ABSTRACT}

Healthy and hygienic surroundings are the requirement of the era wherein overflowing rubbish bins have been a major reason of concern for the people living mostly in developing countries. The cleanliness with respect to rubbish management is lowering enormously due to an increase in the level of population. Open and brimming bins will lead to be a breeding home for germs. Generally, only on a number of the specific days of the week municipal corporations' function on weekly means to pick up trash, irrespective of whether the bins are complete or not. There has been an accelerated growth in the field of technology, and these changes leads to changes in the lifestyle of human beings and which further leads to automation in many tasks. One of the foremost contributors of this automation is the Internet of Things, also referred to as IoT.

This concept is primarily built on the joint working of cloud server and the IoT. Sensors inserted beneath the lid of the trash bins calculate the distance among the lid of the bin and the rubbish level. The usage of this information while the trash level reaches $85 \%$ of the entire capacity, a message from the trash bins will be dispatched to the servers alerting them that the trash bin is filled. Thus, the municipal corporations can send trash collecting vehicle to only to the areas wherein the trash bins are filled, thus saving time in addition to fuel because of enhanced way for rubbish collection rather than traveling to entire blocks to examine each and every trash bin individually. This technology may be implemented into the prevailing trash bins and there is no need to install new trash bins for this purpose and this will carry down the capital investment. Ultimately the cost-effective gadgets like this will be productive in the long run.

Key words: Automation, Cost Effective, Investment, IoT, optimized, Sensors

\section{INTRODUCTION}

The IoT may be considered as a worldwide infrastructure for the information society, permitting superior offerings through connecting (physical and virtual) things primarily based on present and developing interoperable information and communication technology (ICT). Nowadays, because of expeditious growth in the Population, ineptitude of metropolis governments, a deprivation of public awareness and finite investment for programs for waste management, debris disposal has turn out to be a massive reason of problem throughout the world. A voluminous quantity of waste produced is disposed of through means which has an unpropitious impact on the environment. Waste accumulation is so excessive that it turns into a catastrophe if left uncollected. If the rubbish collector does not turn up, a domestic household might likely direct their maidservant to collect the baggage of trash, as it might be an excessive amount of for the bags to be stored within the house.

The servant would likely discard the trash at the end of the street. By seeing that other people will follow the same thing. The vicinity might steadily become a rubbish dump yard, which might change into a heaven for deadly diseases. Open and brimming bins and inefficient waste control will lead to environment pollution which consequently leads to breeding home for many deadly causing diseases. Waste management is a crucial concern that the current economy is confronting with. The proper waste management will aid healthy livelihood and similarly control different types of pollution. According to the solid waste management rule (SWMR), 2016 database, in India the solid waste production in the country ranges from 200 grams to 600 grams per person, every day. Annually the degree of municipal solid waste production is about 62 million tons, of which only 43 million Tons Per Annum (TPA) wastes is assembled. The most common approach of garbage or waste disposal is unintended and unrestrained brazenly being dumped on the lanes or teeming within the rubbish bins etc. 
Deepu K et al., International Journal of Networks and Systems, 8(3), April - May 2019, 83 - 86

The prospect of aquifer contamination can be greater nearby to the landfill vicinity because of the infiltration of leachate. The seepage of the leachate can also change the soil characteristics and also contaminate the soil property. The transportation of waste is an imperative task in waste management. With the help of IoT the municipal corporations can send trash collecting vehicle to only to the areas wherein the trash bins are filled, thus saving time in addition to fuel because of enhanced way for rubbish collection rather than traveling to entire blocks to examine each and every trash bin individually. In view of this, we are right here with a project wherein human and digital brains will be operating mutually in conjunction with the internet of things to automatically and mechanically sense the extent of waste within the garbage bin. The method is that an ID will be given to every garbage bin can with microcontroller chip, as quickly as the rubbish bin will overflow, the local server (from in which all of the rubbish collection vehicles are allocated) will get a notification to drain the rubbish bin. The project will even assist people to win bonus points primarily based on the rubbish weight predisposed of within the rubbish bin, over weight sensor inside the garbage can.

\section{LITERATURE SURVEY}

The garbage system now exits is a system that provide job for a large number of peoples. Most here exits are the road side garbage dumping system, here the persons who dump their garbage on the road side that will make a large type of problems due to the ill effects of it. Here the system is peoples are advised to dump their garbage into the waste bins which are provided at road sides. Most costs which are utilized in waste management is the physical garbage collection from residential and commercial peoples, says Brian Sheridan, Ph.D., Director of Odour Monitoring Ireland, he is a provider of analytic and process engineering services. Also, here in this system the garbage collecting is done in periodic way. Here the provided vehicles are coming in particular days for collecting the garbage and then moves them to the landfill. In some cases, the provided vehicles cannot collect all the wastes because they already filled by the first set of bins. From the experience with these current systems some defects are mentioned below;

a. People put their waste into the garbage bin without any limit, it makes bin to be full. People keep putting in it will make the bin to overflow.

b. The big vehicles which are provided to pick up the waste, which goes to the bins in a locality to collect the garbage even they are no filled just to fulfill their duty.

c. Garbage pickup are coming only in a week in a locality. If any functions occur in that locality will make a huge volume of waste, as a result garbage bins are more likely to fill in some days. This makes bins at that locality keep on overflowing. This makes bad smell and unhealthy environment.

d. The vehicles which provided are goes to collect waste from empty bins may cause the waste of fuel and time.

\section{PROPOSAL}

The main objective of our system is that to make our environment clean and hygienic by making peoples to put their waste into the bins which are provided. Here the smart bin which works with an emerging technology known to be Internet of Things (IoT). The main idea of IoT here used is to provide a link each bin to a regional server in a society. The will put their waste through the flap door provided at front top of the garbage bin. A lid is used to lockup and the sensor circuit will behind the lid, which protected from water and wastes.

An ultrasonic distance sensor which is used to calculate the distance between the garbage pile and the top lid when a person dump waste into the bin and the resultant information is transmitted to the server side by using a microcontroller which fixed with the sensor circuit. The officials will get a notification when the garbage bin fills up to $85 \%$, thus they make necessary actions for collecting waste from that location. As a result, the garbage is not piled up and depending on the number of pickup locations and amount of waste, the vehicles are being assigned.

Here the advantage of our system, we encourage people to put their waste into the waste bin which we provided. For that we implement a reward-based system here. It is the inclination of the general population to ask a typical inquiry" what is in there for me? "or "by what method will it be valuable if I follow it? "when we address this issue individuals consequently pursue our proposed way. As indicated by our plan to make it straightforward we give rewards (focuses) for their waste deposited in the bin. The reward System depends on the sum or weight of waste they are keeping in the trash container which can be determined by the weight sensor at the base of the garbage bin. Individuals need to enlist on the web. In the enlistment procedure, the details of individuals are received just as they would choose the dustbins nearest to them utilizing the GPS.

After the completion of registration, individuals would get a smart card whose ID is connected with the dustbin gets selected at the time of registration. Clients need to streak the card (RFID CARD) on the card reader on the waste bin to get to their record for trash statement. Henceforth by along 
Deepu K et al., International Journal of Networks and Systems, 8(3), April - May 2019, 83 - 86

these lines we can relegate a similar ID code for an individual living in zone 1 and furthermore to an individual living in region 2, as their ID's are connected just to the refuse canisters chosen by them. As per the heaviness of the trash kept, the individual focuses are credited to the online "REBIGS" wallet which is connected to a firm like "PAYTM" or "FREECHARGE" where individuals can trade their points for rebate coupons and different items as well. The report containing the measure of waste stored and the focuses earned is send as a SMS to the phone on a week after week fundamental straightforwardly from web server. One more preferred stand point of this proposed frame work is that the rubbish receptacles which are as of now being used need not be supplanted, yet can be adjusted. Subsequently the expense does not increment and in the meantime, time is likewise spared.

\section{IMPLIMENTATION}

The canny refuse container works with the assistance of couple of sensors joined with a microcontroller which work in connection with one another to get the ideal outcome. At whatever point an individual places trash in the receptacle the ultrasonic sensors present at the highest point of the offer (underneath the top) measures the tallness of the refuse. At the point when the tallness of the rubbish achieves $85 \%$ of the complete stature, the sensor triggers the microcontroller, which thusly sends a notice to the server (kept up by the metropolitan company) demonstrating that the specific container will be full up to the overflow. The area of each canister through the directions is sent alongside the notice to the server. Along these lines the organization can dole out a vehicle nearest to the area of the waste canister.

Likewise, a GPS framework introduced in the vehicle would give the most limited conceivable course to the driver for the pickup to be directed. This won't just spare time, it would likewise diminish the fuel utilization of the vehicles used to lead pickups. The whole setup inside the canister is associated and is fueled by a power bank of higher limit which can be revived and supplanted at regular intervals by staff of the city organization. Every one of these segments are fixed inside the garbage can under the end cover with the end goal that they are not harmed by climate or individuals. Individuals can enlist themselves on the REBIGS site or the Mobile Application and get a brilliant card with a haphazardly produced one of a kind recognizable proof number. This brilliant card is otherwise called RFID card (Radio Frequency Identification card) which contains electronically put away data (for example the remarkable ID number for that specific client). At the point when the clients place waste into the canister they simply need to streak their savvy card before the Card Reader Module to enter the data.
The card per user module peruses the client's number and transfers it to the site alongside the heaviness of the trash saved, which thus is determined by the weight sensor introduced at the base of the waste canister. Along these lines the clients are urged to put the rubbish just in the refuse receptacles in order to get whatever number focuses as could be expected under the circumstances the focuses. The focuses scored by the clients can be recovered for blessing/markdown vouchers on driving web-based business sites like PAYTM and FREECHARGE.

\section{ALGORITHM}

STEP1: First status (empty case)

$\mathrm{Wt}=0$ (weight measured by the sensor)

$\mathrm{Wi}=0$ (previous measure done by the sensor)

STEP2: Dumping by A

Weight dumbed by $\mathrm{A}=5 \mathrm{~kg}$

$\mathrm{Wt}=5, \mathrm{Wi}=0$

Send $(\mathrm{Wt}-\mathrm{Wi})=5 \mathrm{~kg}$ to server

$\mathrm{Wt}=\mathrm{Wi}$

STEP3: Next dumping by B

Weight by $\mathrm{B}=7 \mathrm{~kg}$

$\mathrm{Wt}=12, \mathrm{Wi}=5$

Send $(\mathrm{Wt}-\mathrm{Wi})=7 \mathrm{~kg}$ to server

$\mathrm{Wt}=\mathrm{Wi}$

STEP4: Next dumping by C

Weight dumped by $\mathrm{c}=10 \mathrm{~kg}$

$\mathrm{Wt}=22, \mathrm{Wi}=12$

Send $(\mathrm{Wt}-\mathrm{Wi})=10 \mathrm{~kg}$ to server

$\mathrm{Wt}=\mathrm{Wi}$

STEP5: This continues until the waste are cleared by the authorities. After the range of $\mathrm{Wt}$ and $\mathrm{Wi}$ are reset to 0 automatically.

\section{ADVANTAGES}

a. Individuals persuaded to put their trash just in the waste. 
Deepu K et al., International Journal of Networks and Systems, 8(3), April - May 2019, 83 - 86

b. By thusly we accomplish two creative capacities they are operational productivity and waste decrease.

c. We can wipe out waste flood.

d. Time and fuel can be spared due to upgraded course for trash accumulation.

\section{CONCLUSION}

Urbanization is thriving at a swift pace, as more individuals are inclined to stay in towns and cities. Therefore, it is crucial for a salubrious, hygienic and unpolluted environment. Despite the fact that waste management and public services agencies were around for a long run, they have discerned only transformation with operational coherenceuntil the previous years. In long run the intelligent wastebased system with rewards will provide a high and good output after implementation. We are able to mitigate the pollution cost through the stinking waste that we stumble upon along the street through installing this device of waste disposal and collection. At the same time, it also paves a way for a hygienic and healthy environment. Additionally, the world is made healthy and hygienic and the individuals are rewarded for their benefit.

This concept for the management of wastes is efficient and economical process than the presently employed approach wherein concerned municipal worker has to search for the crammed waste containers manually throughout the different spot in a region/road for checking frequently whether the waste bin is brimmed or not, which is a complicated and tedious process. This automation of waste additionally reduces the human effort and therefore the cost of the entire procedure. This system may be installed at any area effortlessly and within an affordable price and time. This technique facilitates in preserving the waste bin tidy and clean while the bin is completely brimmed.

Therefore, superior facility of accumulating wastes and transportation need to be provided. Due to the fact that this system offers the data while the bin gets completely filled with wastes, it reduces the variety of instances the advent of the vehicle which collects the rubbish. Our work is small however an efficient step for the constructing of a dream metropolis with a hygienic and healthy and really clean and tidy environment. We believe that our offered system will offer excessive income and output after installation with the assistance and support from the government authorities. This system guarantees that whenever anybody leaves the trash inside the dustbin, it automatically transmits notification to the concerned authority. Additionally, it enables us to lower down the pollution. This project suggests an approach to how waste management can be accomplished in an efficient and effective manner.

\section{REFERENCES}

[1] Narayan Sharma, Nirman Singha, Tanmoy Dutta : IJSER Smart Bin Implementation System, Volume 6, Issue 9, September 2015.

[2] Vikarant Bhor, Pankaj Morajkar, Maheshwar Dutta, Dishant Pandya : IJERT Smart Garbage Management System, Volume 4, Issue 3, March 2015. https://doi.org/10.17577/IJERTV4IS031175

[3] Gaikwad Prajakta, Jadhav Kalyani, Machale Snehal: IJERT, Volume 4, Issue 3, March 2015.

https://doi.org/10.17577/IJERTV4IS031135

[4] Jebah Kumar, Abishlin Blessy : IJCSIT, Volume 5, 2014.

[5] Kanchan Mahajan, J.S. Chitode: IJIRSET, Waste Bin Monitoring System Using Integrated Technologies, Volume 3, Issue 7, July 2014.

[6] Marian Look, “Trash Plant: India”, earth911 B.

[7] Adil Bashir, Shoaib Amin Banday Ab. Rouf Khan, Mohammad Shafi: IJRITCC, Concept, Design and Implementation of Automatic Waste Management System, Volume 1, Issue 7, July 2013.

[8] Insung Hong, Sunghoi Park, Beomseok Lee, Jaekeun Lee, Daebeom Jeong, and Sehyun Park : The Scientific World Journal, IoT-Based Smart Garbage System for Efficient Food Waste Management, Volume 2014, Article ID 646953. https://doi.org/10.1155/2014/646953 